University of Nebraska - Lincoln

DigitalCommons@University of Nebraska - Lincoln

Drought Mitigation Center Faculty Publications Drought - National Drought Mitigation Center

2012

\title{
Vegetation Drought Response Index An Integration of Satellite, Climate, and Biophysical Data
}

\author{
Brian D. Wardlow \\ University of Nebraska - Lincoln, bwardlow2@unl.edu \\ Tsegaye Tadesse \\ University of Nebraska - Lincoln, ttadesse2@unl.edu \\ Jesslyn F. Brown \\ U.S. Geological Survey \\ Karin Callahan \\ University of Nebraska-Lincoln, kcallahan2@unl.edu \\ Sharmistha Swain \\ University of Nebraska-Lincoln
}

See next page for additional authors

Follow this and additional works at: https://digitalcommons.unl.edu/droughtfacpub

Wardlow, Brian D.; Tadesse, Tsegaye; Brown, Jesslyn F.; Callahan, Karin; Swain, Sharmistha; and Hunt, Eric, "Vegetation Drought Response Index An Integration of Satellite, Climate, and Biophysical Data" (2012). Drought Mitigation Center Faculty Publications. 107.

https://digitalcommons.unl.edu/droughtfacpub/107

This Article is brought to you for free and open access by the Drought -- National Drought Mitigation Center at DigitalCommons@University of Nebraska - Lincoln. It has been accepted for inclusion in Drought Mitigation Center Faculty Publications by an authorized administrator of DigitalCommons@University of Nebraska - Lincoln. 


\section{Authors}

Brian D. Wardlow, Tsegaye Tadesse, Jesslyn F. Brown, Karin Callahan, Sharmistha Swain, and Eric Hunt 
Published in Remote Sensing of Drought: Innovative Monitoring Approaches, edited by Brian D. Wardlow, Martha C. Anderson, \& James P. Verdin (CRC Press/Taylor \& Francis, 2012).

This chapter is a U.S. government work and is not subject to copyright in the United States.

Authors:

\section{Brian D. Wardlow}

National Drought Mitigation Center

School of Natural Resources

University of Nebraska-Lincoln

Lincoln, Nebraska

\section{Tsegaye Tadesse}

National Drought Mitigation Center

School of Natural Resources

University of Nebraska-Lincoln

Lincoln, Nebraska

\section{Jesslyn F. Brown}

Earth Resources Observation and Science Center

U.S. Geological Survey

Sioux Falls, South Dakota

\section{Karin Callahan}

National Drought Mitigation Center

Center for Advanced Land Management Information Technology

School of Natural Resources

University of Nebraska-Lincoln

Lincoln, Nebraska

\section{Sharmistha Swain}

National Drought Mitigation Center

School of Natural Resources

University of Nebraska-Lincoln

Lincoln, Nebraska

\section{Eric Hunt}

National Drought Mitigation Center

School of Natural Resources

University of Nebraska-Lincoln

Lincoln, Nebraska 


\section{Vegetation Drought Response Index An Integration of Satellite, Climate, and Biophysical Data}

Brian D. Wardlow, Tsegaye Tadesse, Jesslyn F. Brown, Karin Callahan, Sharmistha Swain, and Eric Hunt

\section{CONTENTS}

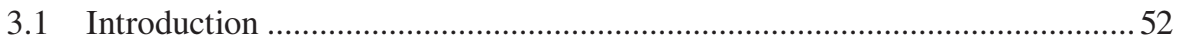

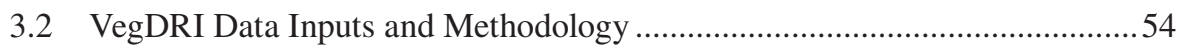

3.2.1 Overview of the VegDRI Concept.....................................................54

3.2.2 VegDRI Classification Scheme......................................................56

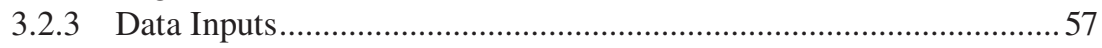

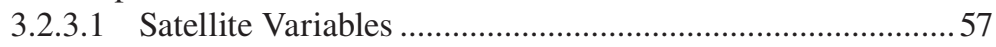

3.2.3.2 Climate Variables.............................................................. 58

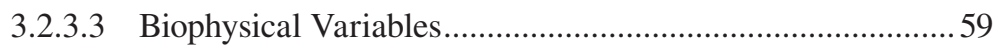

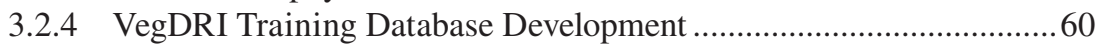

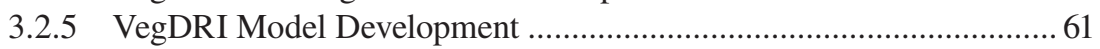

3.2.6 VegDRI Model Implementation and Mapping ..............................6 62

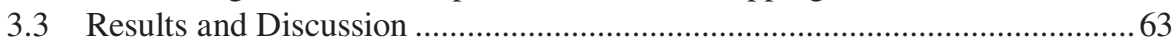

3.3.1 Statistical Analysis of Historical VegDRI Model

Performance across the United States ...........................................6 63

3.3.2 National-Level VegDRI: An Example from 2009 ............................6 64

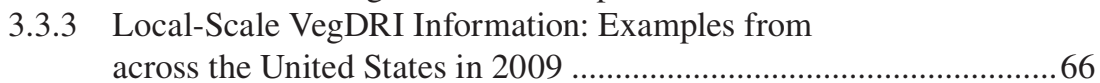

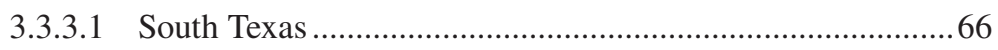

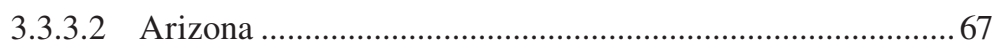

3.3.3.3 Minnesota and Wisconsin.................................................6 68

3.4 Enhancing VegDRI with MODIS Satellite Data .........................................69

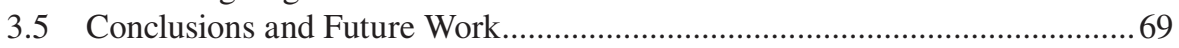

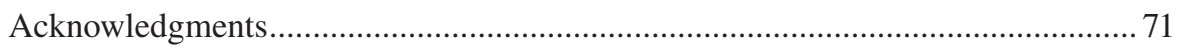

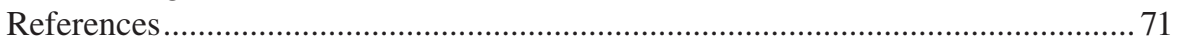




\subsection{INTRODUCTION}

Drought is a normal, recurring feature of climate in most parts of the world (Wilhite, 2000) that adversely affects vegetation conditions and can have significant impacts on agriculture, ecosystems, food security, human health, water resources, and the economy. For example, in the United States, 14 billion-dollar drought events occurred between 1980 and 2009 (NCDC, 2010), with a large proportion of the losses coming from the agricultural sector in the form of crop yield reductions and degraded hay/pasture conditions. During the 2002 drought, Hayes et al. (2004) found that many individual states across the United States experienced more than $\$ 1$ billion in agriculture losses associated with both crops and livestock. The impact of drought on vegetation can have serious water resource implications as the use of finite surface and groundwater supplies to support agricultural crop production competes against other sectoral water interests (e.g., environmental, commercial, municipal, and recreation). Drought-related vegetation stress can also have various ecological impacts. Prime examples include widespread piñon pine tree die-off in the southwest United States due to protracted severe drought stress and associated bark beetle infestations (Breshears et al., 2005) and the geographic shift of a forest-woodland ecotone in this region in response to severe drought in the mid-1950s (Allen and Breshears, 1998). Tree mortality in response to extended drought periods has also been observed in other parts of the western United States (Guarin and Taylor, 2005), as well as in boreal (Kasischke and Turetsky, 2006), temperate (Fensham and Holman, 1999), and tropical (Williamson et al., 2000) forests. Droughts have also served as a catalyst for changes in wildfire activity (Swetnam and Betancourt, 1998; Westerling et al., 2006) and invasive plant species establishment (Everard et al., 2010).

Monitoring drought stress of vegetation is a critical component of proactive drought planning designed to mitigate the impact of this natural hazard. Approaches that characterize the spatial extent, intensity, and duration of drought-related vegetation stress provide essential information for a wide range of management and planning decisions. For example, such information could be used by agricultural producers and water resource managers to adjust crop irrigation schedules and by ranchers to determine stocking rates and grazing rotations for cattle. In addition, this knowledge allows natural resource managers to implement best management practices under drought conditions and other decision makers to better target assistance and response activities (e.g., release of Conservation Reserve Program grasslands for emergency grazing or early detection of hot spots for wildfires) in a timely manner.

For more than 20 years, satellite-based remote sensing has been widely used for many large-area vegetation characterization applications (e.g., land cover classification, biophysical estimates, and phenology) including drought monitoring. Satellitebased observations from global imagers such as the Advanced Very High Resolution Radiometer (AVHRR) and the more recent Medium Resolution Imaging Spectrometer (MERIS), Moderate Resolution Imaging Spectroradiometer (MODIS), and SPOT (Satellite Pour l'Observation de la Terre) Vegetation instruments have provided a neardaily, global coverage of spatially continuous spectral measurements to complement point-based weather station observations that have been used to generate traditional, climate-based drought indices such as the Palmer Drought Severity Index (PDSI) (Palmer, 1965) and the Standardized Precipitation Index (SPI) (McKee et al., 1995). 
Over this period, a number of remote sensing-based vegetation indices (VIs) have been developed from various spectral band combinations to monitor vegetation health.

The Normalized Difference Vegetation Index (NDVI) (Rouse et al., 1974) has been the most widely used VI for large-area vegetation monitoring (e.g., Tucker et al., 1985; Townshend et al., 1987; Reed et al., 1996; Jakubauskas et al., 2002). NDVI is a simple, two-band mathematical transformation that capitalizes on the differential response of chlorophyll absorption and internal spongy mesophyll layer reflectance from plant leaves in the visible red and near infrared (NIR) spectral regions, respectively. A large body of research has found that NDVI fluctuations over time are strongly correlated with climate variations (Peters et al., 1991; Yang et al., 1998; McVicar and Bierwirth, 2001; Ji and Peters, 2003), indicating that this index is an effective measure of climate-related vegetation changes. Over the past two decades, several operational AVHRR-derived NDVI products have been developed for large-area vegetation monitoring, including the Global Inventory Modeling and Mapping Studies (GIMMS) global NDVI data set (Tucker et al., 2005), the Famine and Early Warning System Network (FEWS NET) regional NDVI data sets (e.g., Africa, Afghanistan, and Latin America), and national NDVI products over Australia and United States (Eidenshink, 2006) produced by the Australian Bureau of Meteorology and U.S. Geological Survey (USGS), respectively.

The Vegetation Health Index (VHI) (Kogan, 1995), which incorporates both NDVI and brightness temperature (BT) data collected by AVHRR, is another index that has been applied to assess national- to continental-scale drought conditions (Liu and Kogan, 1996; Kogan, 1997; Seiler et al., 1998; Unganai and Kogan, 1998; Kogan, 2002). The VHI concept assumes an inverse relationship between NDVI and BT because higher land surface temperatures (LSTs) tend to negatively impact vegetation vigor (and decrease NDVI), which can be indicative of a drought stress signal because of reduced evapotranspiration (ET). However, Karnieli et al. (2006, 2010) found VHI had limited utility in "energy limited" environments (e.g., high latitude or elevation locations) where LST and NDVI exhibit a positive relationship and was most useful for locations where water was the primary limiting factor of vegetation growth. Several other methods of integrating NDVI and LST data from AVHRR and MODIS have also been tested for drought monitoring that include simple division (McVicar and Bierwirth, 2001), two-dimensional geometric expressions (Karnieli and Dall'Olmo, 2003), and ratios (Wan et al., 2004) between these two variables.

The launch of MODIS, with an increased number of land-related spectral bands and expanded spectral coverage into the shortwave-infrared region (SWIR), led to the development of several new VIs incorporating SWIR observations. MODIS has two SWIR bands that are sensitive to changes in plant (Band 6: 1628-1652 nm) and soil (Band 7: 2105-2155 nm) water content, respectively. Gao (1996) developed the Normalized Difference Water Index (NDWI), which capitalizes on the differential response of the NIR (i.e., high reflectance by intercellular spaces) and the SWIR (i.e., high absorption by plant water content) reflectances in healthy vegetation. In a study over grasslands, $\mathrm{Gu}$ et al. (2007) found NDWI to be slightly more sensitive than NDVI to the onset of drought stress. Gu et al. (2008) extended both the NDVI and NDWI concepts by integrating both into an index called the Normalized Difference Drought Index (NDDI). Wang et al. (2007) built upon the original NDWI concept by developing a three-band 
index called the Normalized Multi-band Drought Index (NMDI), which incorporates data from both of MODIS' SWIR bands, as well as the NIR band. The NMDI utilizes the difference between the two SWIR bands, which are sensitive to soil and plant water content, respectively. The relative difference between these two SWIR bands changes according to fluctuation in both the soil and plant water content.

Collectively, this body of work illustrates the value of satellite-based VI observations for assessing vegetation conditions and the considerable emphasis that has been placed on developing new VIs in support of drought monitoring. However, two major challenges exist among all these satellite-based VIs in terms of applying them for drought monitoring. The first challenge is establishing the appropriate threshold(s) that discriminates between drought and nondrought conditions, as well as varying levels of drought stress (e.g., moderate, severe, and extreme). Typically, a relative VI value or a departure of a VI value from a baseline (e.g., low percentage of the average historical VI value) is used as an indicator of drought stress instead of classifying specific levels of drought severity. Selection of thresholds to classify drought conditions using VI information is difficult because they can vary by land cover type, geographic location, and season. The second challenge is the ability to discriminate drought-impacted areas from other locations experiencing vegetation stress due to other causes solely from remotely sensed VI information. A number of environmental factors (e.g., fire, flooding, hail, pests, plant disease, and humaninduced land cover/use changes) can produce negative VI anomalies (Peters et al., 2000; Domenikiotis et al., 2003; Wang et al., 2003; Goetz et al., 2006; Franke and Menz, 2007) that mimic a drought stress signal. Ancillary information such as climate data or ground observations (e.g., field reports of crop conditions) is needed to better define these negative VI anomalies within a drought context.

This chapter presents a new hybrid index called the Vegetation Drought Response Index (VegDRI) that integrates traditional remote sensing-based VI observations and climate-based drought index data with several general biophysical characteristics of the environment to characterize "drought-related" vegetation stress (Brown et al., 2008). VegDRI was designed to capitalize on the valuable spatiotemporal vegetation condition information contained in multitemporal NDVI data while focusing on the drought component of these conditions through the addition of climate and biophysical data. VegDRI overcomes the interpretation difficulties encountered using traditional remote sensing-based VIs and classifies vegetation drought severity using an objective, quantitative classification scheme. A review of VegDRI's specific data inputs, classification scheme, and modeling approach is presented in this chapter along with case examples of VegDRI results from 2009 across the United States to illustrate the performance and utility of this new drought VI.

\subsection{VegDRI DATA INPUTS AND METHODOLOGY}

\subsubsection{Overview of the VeGDRI Concept}

VegDRI targets the effects of drought on vegetation by collectively analyzing general vegetation conditions as observed in satellite-derived VI data and the level of dryness expressed in climate-based drought indices for a specific location. 
Additional biophysical/environmental characteristics such as ecoregion, elevation, land use/land cover (LULC) type, and soil type are also considered because they can influence climate-vegetation interactions. This integrated approach was developed to capitalize on the strengths of both satellite- and climate-based indices that have been traditionally used for drought monitoring. The set of data inputs used to calculate VegDRI can be categorized into three components: satellite, climate, and biophysical. The satellite component provides spatially detailed information about the distribution and general health of vegetation from $1 \mathrm{~km}$ AVHRR NDVI data. The climate component consists of two commonly used drought indices, the PSDI and SPI, which provide a measure of dryness. Specifically, the PDSI is used to train the empirically-based VegDRI models, providing an eight-category drought severity classification system widely recognized by the drought community that ranges from extremely moist to extreme drought conditions. The biophysical component comprises several biophysical variables that reflect different terrestrial characteristics that can influence the response of vegetation to drought. Table 3.1 lists the specific VegDRI input variables, which will be further described in this section along with a detailed description of the VegDRI methodology. This methodology consists of four primary steps: (1) creation of a historical database of input variables for model development, (2) generation of biweekly, empirically based VegDRI models, (3) generation of near-real-time gridded data inputs, and (4) application of model to gridded inputs to produce $1 \mathrm{~km}$ VegDRI maps (Figure 3.1).

\section{TABLE 3.1 \\ Input Variables for the Biophysical, Climate, and Satellite Components of VegDRI}

\begin{tabular}{lccc} 
Data Set & \multicolumn{1}{c}{ Source } & Format & $\begin{array}{c}\text { Temporal } \\
\text { Resolution }\end{array}$ \\
Climate component variables & & & \\
SPI & ACIS/NADSS & ASCII (at sites) & Biweekly \\
PDSI_self-calibrated & ACIS/NADSS & ASCII (at sites) & Biweekly
\end{tabular}

Satellite component variables

$\begin{array}{llll}\text { PASG } & \text { AVHRR NDVI } & 1 \mathrm{~km} \text { raster } & \text { Biweekly } \\ \text { SOSA } & \text { AVHRR NDVI } & 1 \mathrm{~km} \text { raster } & \text { Annual }\end{array}$

Biophysical component variables

\begin{tabular}{llll} 
NLCD & $\begin{array}{c}\text { National Land } \\
\text { Cover Database }\end{array}$ & $1 \mathrm{~km}$ raster & Static \\
Soil AWC & STATSGO & $1 \mathrm{~km}$ raster & Static \\
IrrAg & USGS MIrAD & $1 \mathrm{~km}$ raster & Static \\
Ecological regions (ECO) & EPA ecoregions & $1 \mathrm{~km}$ raster & Static \\
Elevation (DEM) & & $1 \mathrm{~km}$ raster & Static \\
\hline
\end{tabular}




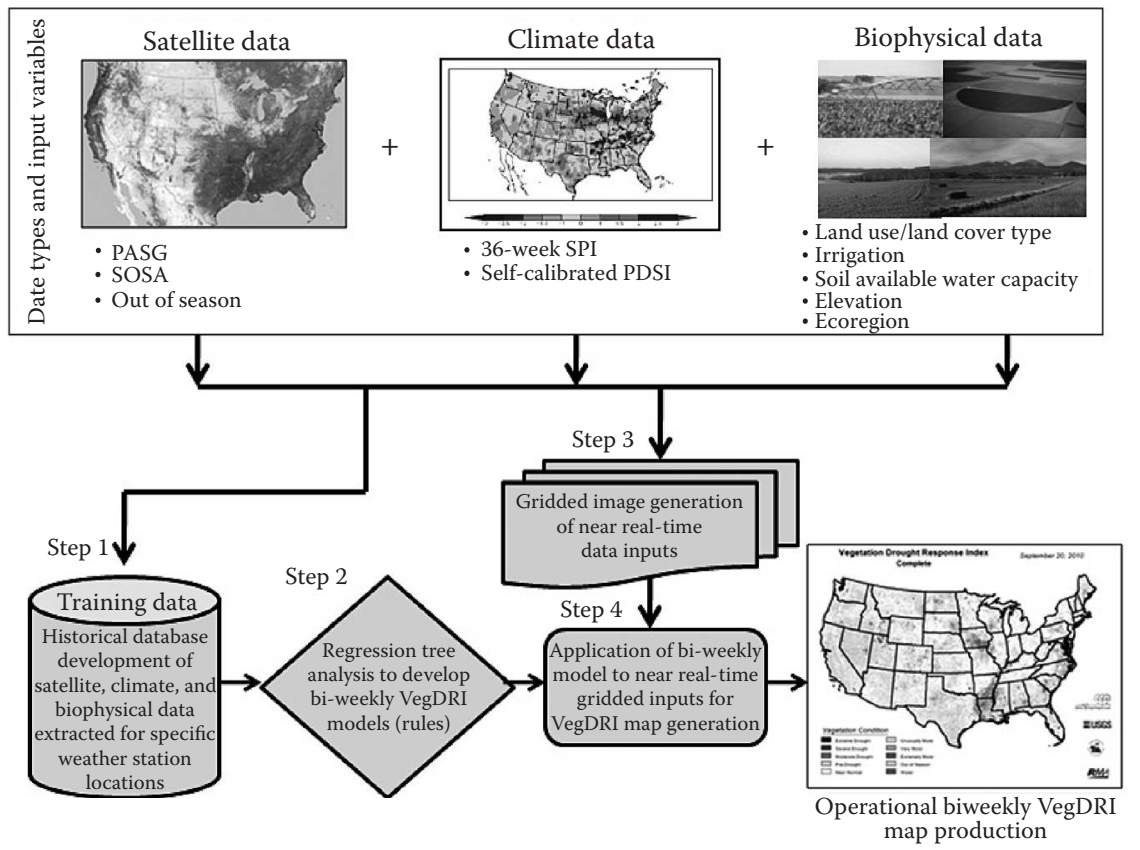

FIGURE 3.1 Overview of the data inputs and methodology of VegDRI.

\subsubsection{VegDRI Classification Scheme}

VegDRI has eight vegetation condition classes (Table 3.2) based on a modified version of the PDSI classification system (Palmer, 1965). There are three classes of drought severity (moderate, severe, and extreme), as well as a predrought class that represents the dry side of near-normal class value range. The predrought class was included to highlight areas that may be nearing initial drought conditions. VegDRI also has four nondrought classes (normal, unusually, very, and extremely moist) that characterize

TABLE 3.2

\section{VegDRI Classification Scheme and Class} Value Ranges

$\begin{array}{lc}\text { VegDRI Class Names } & \text { Value Range } \\ \text { Extreme drought } & <-4 \\ \text { Severe drought } & -4 \text { to }-3 \\ \text { Moderate drought } & -3 \text { to }-2 \\ \text { Predrought } & -2 \text { to }-1 \\ \text { Near normal } & -1 \text { to }+2 \\ \text { Unusually moist } & +2 \text { to }+3 \\ \text { Very moist } & +3 \text { to }+4 \\ \text { Extremely moist } & >+4\end{array}$


locations with normal to better than normal vegetation conditions, as well as areas of excessively wet conditions that could result in poor vegetation conditions due to flooding or water logging. An "out of season" (OS) class is also included to identify time periods for a given location when the vegetation is dormant (e.g., winter months) and VegDRI values are not calculated. OS is objectively defined through the historical analysis of time-series AVHRR NDVI data, which is discussed later in this section.

\subsubsection{Data InPUTS}

\subsubsection{Satellite Variables}

A 20 year time series of biweekly, composited $1 \mathrm{~km}$ AVHRR NDVI data (Eidenshink, 2006) is used to calculate three vegetation-related metrics used in the VegDRI model, which include Percent Annual Seasonal Greenness (PASG), Start of Season Anomaly (SOSA), and OS. Prior to the calculation of these metrics, the NDVI time series is smoothed using a weighted least squares regression technique (Swets et al., 1999) to minimize noise and other artifacts (e.g., residual clouds) commonly found in the AVHRR data (Los et al., 1994) while maintaining the major multitemporal features of the original NDVI data.

\subsection{Percent Annual Seasonal Greenness}

The PASG provides a measure of how vegetation conditions for a specific biweekly period in a given year compare to the historical average conditions for the same period over the 20 year record of AVHRR NDVI observations. In order to calculate the PASG for each period, a historical median growing season window for each $1 \mathrm{~km}$ pixel in the AVHRR imagery is determined by identifying the Start and End Of Season Time (SOST and EOST) day of year (DOY) from annual AVHRR NDVI time series data using a moving-window averaging technique (Reed et al., 1994). A seasonal greenness (SG) metric, which represents the accumulated NDVI above a background NDVI baseline (i.e., nongrowing season or "latent" NDVI contributed from the soil background and/or atmospheric effects that has little to no biophysical meaning related to vegetation) across each 14 day period, is then calculated starting from the historical SOST DOY for each year in the historical record. SG is calculated sequentially for each period across the year until the EOST DOY, and the SG value for a specific period $\left(\mathrm{SG}_{\mathrm{P} n \mathrm{Y} n}\right.$, the $\mathrm{SG}$ for biweekly period $n\left(\mathrm{P}_{n}\right)$ in year $\left.n\left(\mathrm{Y}_{n}\right)\right)$ represents the sum of the SG for the current and all preceding biweekly periods in the growing season. For each biweekly period, a historical mean $\mathrm{SG}\left(\mu \mathrm{SG}_{\mathrm{P} n}\right)$ is calculated from the 20 yearly SG values. The 20 year record of PASG values for each period-year combination is then produced using the following equation:

$$
\mathrm{PASG}_{\mathrm{P} n \mathrm{Y} n}=\left(\frac{\mathrm{SG}_{\mathrm{P} n \mathrm{Y} n}}{\mu \mathrm{SG}_{\mathrm{P} n 0}}\right) \times 100 .
$$

Brown et al. (2008) provide additional details regarding the PASG calculations. A low PASG value (e.g., <50\%) for a specific biweekly period indicates belownormal (stressed) vegetation conditions compared to the historical conditions for 
that period, while high PASG values greater than $100 \%$ reflect above-average (or nonstressed) vegetation conditions.

\subsection{Start of Season Anomaly}

The SOSA represents the departure in the SOST for a specific year $\left(\mathrm{SOST}_{n}\right)$ from

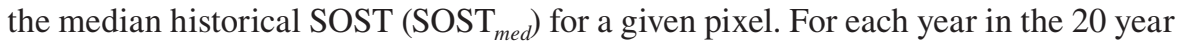
time series, the pixel-level SOSA ( $\mathrm{SOSA}_{n}$ ) expressed in number of days is calculated using the following equation:

$$
\mathrm{SOSA}_{n}=\mathrm{SOST}_{n}-\mathrm{SOST}_{m e d}
$$

The SOSA is included in the VegDRI model to distinguish areas that have a normal start of season and are experiencing low PASG because of interannual climatic variations (e.g., drought or cold early-season temperatures) from areas that experience an unusually late SOST because of nonclimate-related factors (e.g., LULC change or changes in management practices) that might result in a comparably low PASG.

\subsection{Out of Season}

The OS metric represents the nongrowing season period when vegetation is dormant. A historical median OS period is determined for each pixel using the SOST and EOST DOYs calculated for the PASG. The OS is defined as the period from EOST DOY (e.g., DOY 305 or November 1) to the SOST DOY of the next year (e.g., DOY 90 or March 31). During the OS for a given pixel, historical data are excluded from VegDRI model development, and no VegDRI values are calculated in the maps for biweekly periods within this temporal window. Excluding VegDRI calculations during the OS was implemented to avoid "false positive" drought signals from being depicted in the maps during periods of the year when the vegetation is not photosynthetically active, resulting from fluctuations in the NDVI (and resultant PASG) associated with nonvegetation-related factors (e.g., soil background and angular effects).

\subsubsection{Climate Variables}

The self-calibrated PDSI and the SPI were incorporated into VegDRI as indicators of climatic dryness. Historical data for both indices from 2417 weather station locations across the United States (3.2) were acquired from the Applied Climate Information System (ACIS) (http://www.rcc-acis.org/) (Hubbard et al., 2004). To ensure that high-quality historical time-series data are incorporated into VegDRI model development, only data from stations with a minimum 30 year data record and less than $10 \%$ missing observations are used. For each station, a 20 year time series of selfcalibrated PDSI and SPI was calculated on a biweekly time step consistent with PASG calculations.

\subsection{Standardized Precipitation Index}

The SPI was designed to quantify precipitation anomalies over multiple time intervals (e.g., 1-12 month periods) based on fitting a long-term precipitation record at a given location over a specified interval to a probability distribution, which is then 
transformed into a gamma distribution so that the mean SPI value for that location and time period is 0 (McKee et al., 1995). SPI values are positive if the precipitation over a specific time period is higher than the historical average precipitation over that same period and negative if precipitation is less than the historical mean. The strength of the SPI is its temporal flexibility to assess conditions over short, intermediate, and long time intervals. A 36 week SPI was selected for VegDRI after exhaustive statistical testing of all SPI time intervals spanning from 1 to 52 weeks for the 2417 stations. Selection was based on the SPI that had a consistently high correlation coefficient value across all growing season periods.

\subsection{Palmer Drought Severity Index}

The PDSI is a prominent drought index that has been widely used to assess agricultural drought in the United States (Keyantash and Dracup, 2002). The PDSI is calculated from a simple supply-and-demand model of water balance that integrates precipitation and temperature information, as well as the available water holding capacity of the soil at a given location (Palmer, 1965). A new self-calibrated PDSI (Wells et al., 2004) is used in VegDRI, which calibrates the constants and duration factors in the PDSI computations to the local environmental characteristics of a specific location while still retaining the objectives of the original PDSI. These local adjustments improve the spatial comparability of PDSI values and calibrate the index so that extreme dry and wet events have a comparable rate of occurrence at any location (Guttman et al., 1992), providing a more consistent national PDSI data input for the VegDRI models.

\subsubsection{Biophysical Variables}

\subsection{Land Use/Land Cover}

The LULC variable was incorporated into VegDRI to reflect the variety of seasonal cycles and climate-vegetation responses exhibited by different LULC types. A $1 \mathrm{~km}$ LULC map was developed from the USGS $30 \mathrm{~m}$ National Land Cover Dataset (NLCD) circa 2001 (Homer et al., 2004). For each $1 \mathrm{~km}$ pixel in the AVHRR grid over the conterminous United States (CONUS), the majority LULC class among the $30 \mathrm{~m}$ NLCD data was determined and assigned to that $1 \mathrm{~km}$ pixel. Some thematic classes in the original NLCD classification scheme were merged (e.g., emergent herbaceous and woody wetland classes assigned to a single wetland class) to create more general LULC classes for model development.

\subsection{Irrigated Agriculture}

An irrigated agriculture (IrrAg) variable was integrated into VegDRI to differentiate irrigated locations, which are less susceptible to drought stress because of targeted water applications, from rainfed agricultural areas. A $1 \mathrm{~km}$ map depicting the spatial distribution of IrrAg was generated from a $250 \mathrm{~m}$ MODIS Irrigated Agriculture Dataset (MIrAD) developed from a combination of MODIS NDVI data, USDA county irrigation statistics, and LULC information (Brown et al., 2009). The $1 \mathrm{~km}$ IrrAg map represents the percentage of irrigated $250 \mathrm{~m}$ MIrAD pixels contained within each $1 \mathrm{~km}$ pixel footprint. 


\subsection{Soil Available Water Capacity}

The available water capacity (AWC) variable is used to reflect the potential of the soil to hold moisture that is available to plants, which influences the susceptibility of vegetation to drought stress. A $1 \mathrm{~km}$ AWC map was developed by extracting the AWC values for the total soil column from the State Soil Geographic (STATSGO) database for each soil map unit (USDA, 1994) and converting the map unit polygons to a $1 \mathrm{~km}$ raster grid.

\subsection{Ecoregion}

The ecoregion variable provides a geographic framework to account for the considerable variability in environmental conditions encountered across the CONUS that can influence the level of drought stress experienced at a given location. For example, two locations (e.g., High Plains versus Flint Hills) may be assigned to same general grassland class by the LULC variable but may have differing responses to drought because they represent different general grassland types (e.g., shortgrass versus tallgrass prairie) with different dominant species compositions (e.g., coolversus warm-season grasses) that have acclimated to the collective environmental conditions of the area (e.g., climate, soils, and topography). A $1 \mathrm{~km}$ ecoregion grid was created from Omernik Level III ecoregion vector data (Omernik, 1987), which divides the CONUS into a series of geographic regions with similar ecosystems and environmental resources defined using both abiotic (e.g., physiography) and biotic (e.g., plant species) criteria.

\subsection{Elevation}

A digital elevation model (DEM) consisting of a $1 \mathrm{~km}$ raster grid of evenly spaced elevation values derived from the USGS $30 \mathrm{~m}$ DEM is included to account for influences of elevation on vegetation types and their sensitivity to drought.

\subsubsection{VegDRI Training Database Development}

A training database of all climate, satellite, and biophysical data discussed earlier was extracted and assembled for the 2417 weather station locations in Figure 3.2. Historical, point-based PDSI and SPI data were calculated for each station and sequentially ordered by biweekly period for each year in the database. Data were also extracted from the gridded satellite and biophysical data sets at the location of each weather station. A $3 \times 3$ pixel window centered on each station location was used to calculate the average value across all pixels in the window for continuous variables (e.g., PASG) and the majority value for categorical variables (e.g., LULC). Pixels within the window classified as urban or water in the LULC grid or flagged to be OS for a specific biweekly period were excluded from the mean or majority zonal calculations for that period. Data values associated with both urban and water locations were excluded because both LULC types are representative of primarily nonvegetated areas that are not the monitoring target for VegDRI. Pixels flagged to be OS for a specific biweekly period were also removed or excluded from the window average for that period because of the nonvegetated spectral signal detected from 


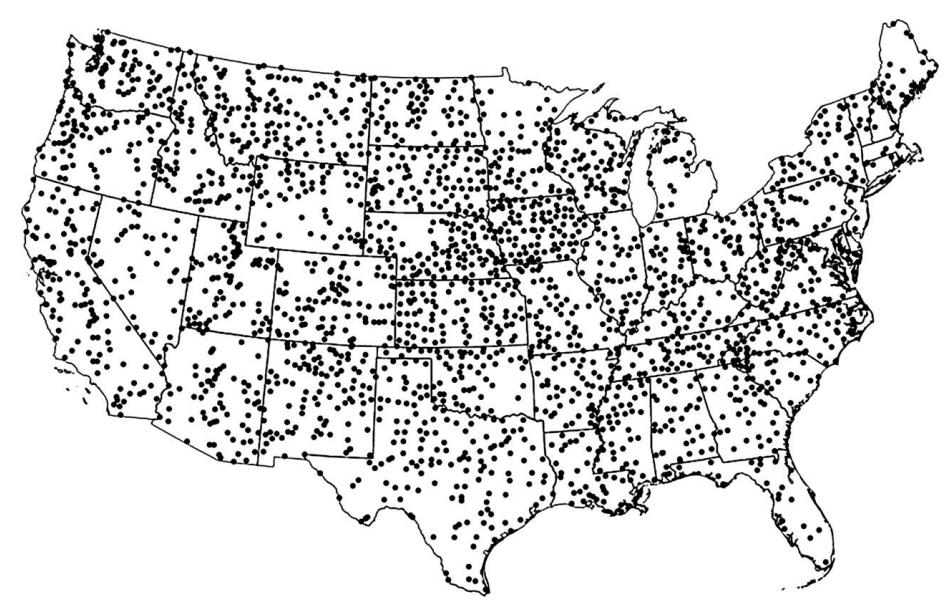

FIGURE 3.2 Geographic location of the 2417 weather station locations used to develop the empirical VegDRI models.

the pixel at that time. A 20 year historical time series of biweekly PASG and OS values was calculated for each station using this approach and sequentially ordered in the same manner as the climate data. For each year in the time series, a SOSA value was calculated for each station location and held constant for all "in-season" biweekly periods for that year. The biophysical variable values calculated for each station were held static across the 20 year period. Historical records of all stations in the database were then temporally subset into 26 biweekly periods (e.g., biweekly period 1: January 1-14) across the calendar year to develop a series of separate, biweekly VegDRI models.

\subsubsection{VegDRI Model Development}

For each biweekly period, a commercial Classification and Regression Tree (CART) algorithm called Cubist (Quinlan, 1993) was used to analyze the historical data in the training database for that specific period and generate a rule-based, piecewise linear regression VegDRI model. Each model incorporates historical data for the "dynamic" climate and satellite-based variables while holding the biophysical variables constant over a four-biweek window that includes the current biweekly period (e.g., biweek 10) plus the three prior biweekly periods (e.g., biweeks 7, 8, and 9) in the calendar year. As discussed earlier, the self-calibrated PDSI serves as the dependent variable in these empirical-based models, providing a well-established classification system for VegDRI to categorize varying levels of drought severity on vegetation based on the analysis of the other biophysical, climate, and satellite variables. Twenty-six period-specific VegDRI models were developed. The Cubistderived models consist of an unordered set of rules, with each rule having the syntax "if $x$ conditions are met then use the associated linear regression model" to calculate 
the VegDRI value. The following is an example of one of many rules generated for a specific biweekly period:

Rule 1:

If land cover in \{Grassland, Pasture/Hay, Row Crops\}

Ecoregion in \{western High Plains, central Great Plains\}

36 week SPI $\leq-1.4$

AWC $\leq 4.5$

$\mathrm{PASG} \leq 50$

then VegDRI $=-3.5+0.6$ PASG +1.48 SPI -0.14 AWC +0.25 percent irrigated

In other words, if the data associated with a case (i.e., pixel) meet the threshold criteria for the three continuous variables and are represented by one of the three land cover types and either ecoregion, then the following linear regression equation is used to calculate a VegDRI value. Most period-specific VegDRI models comprise 30-40 rules. If two or more rules apply to a case, then all linear regression equations are used to calculate a series of values that are averaged to determine the final VegDRI value. It should be noted that some rules and/or associated linear regression equations may not use all the independent variables. For example, in the rule shown earlier, elevation and SOSA are not used. However, each independent variable is incorporated into a subset of the multiple rules and regression equations that are collectively utilized to calculate the final VegDRI value.

\subsubsection{VegDRI Model Implementation and Mapping}

The rules from a biweekly VegDRI model are then applied to the set of gridded image data inputs (listed in Table 3.1) for the corresponding period using MapCubist software developed at the USGS Earth Resources Observation and Science (EROS) Center to produce a $1 \mathrm{~km}$ VegDRI map. For the SPI variable, which is acquired as a point-based index value from weather station data, a $1 \mathrm{~km}$ raster image is generated using an inverse distance weighting (IDW) interpolation method. During model implementation to the gridded image data, the values of all the input variables associated with each pixel are considered to determine the specific rule(s) and corresponding linear regression equation(s) to be applied at the pixel level. This process is repeated until all $1 \mathrm{~km}$ pixels in the image domain have been assigned a VegDRI value.

The VegDRI map is the result of inverting the empirically based regression models, which describe the historical relationship between PDSI and the other climate, environmental, and satellite input variables for known locations (i.e., weather station locations). Although the models are applied at the pixel level during the mapping phase, collectively the integration of these variables results in landscape-level drought depictions across the image domain. In VegDRI's conceptual design, the remote sensing inputs provide high spatial resolution inputs of vegetation patterns and conditions across the landscape, which add structure to $1 \mathrm{~km}$ VegDRI maps when combined with the coarser precipitation patterns represented in the interpolated SPI grid. The spatial patterns represented by the other static environmental variables in the image domain also add spatial structure to maps by providing geographic stratification of the relationship between the remote sensing inputs (i.e., PASG and SOSA) and SPI to estimate PDSI values across the CONUS in the $1 \mathrm{~km}$ VegDRI map generated in this final mapping step. 


\subsection{RESULTS AND DISCUSSION}

\subsubsection{Statistical Analysis of Historical VegDRI Model Performance across the United States}

Assessment of the statistical accuracy of the national-level, biweekly VegDRI models over the CONUS for a 20 year study period (1989-2008) is presented in Figure 3.3. This analysis was conducted to determine how well the VegDRI model was able to reproduce self-calibrated PDSI classifications at weather station locations across the CONUS. An $x$-fold cross-validation technique (Kohavi, 1995) using "hold out" years was used to assess VegDRI's historical performance across the growing season for the 2417 weather station locations in Figure 3.2. For each biweekly period, 20 validation iterations (or folds) were performed by using 19 years of historical data to train a model (e.g., 1990-2008) and one independent "hold out" year (e.g., 1989) to determine VegDRI's predictive accuracy across all stations. A different hold-out year was selected for each iteration, allowing every year in the 20 year record to be withheld for testing. Correlation coefficient results for the primary growing season periods over the CONUS are presented for each biweekly period in Figure 3.3. The Pearson correlation coefficient $(r)$ values for each date represent the mean correlation between the predicted and observed VegDRI values across the 20 year period for all station locations.

The correlation results show that the VegDRI models had a relatively high predictive accuracy across the growing season with $r$ values greater than 0.75 for all

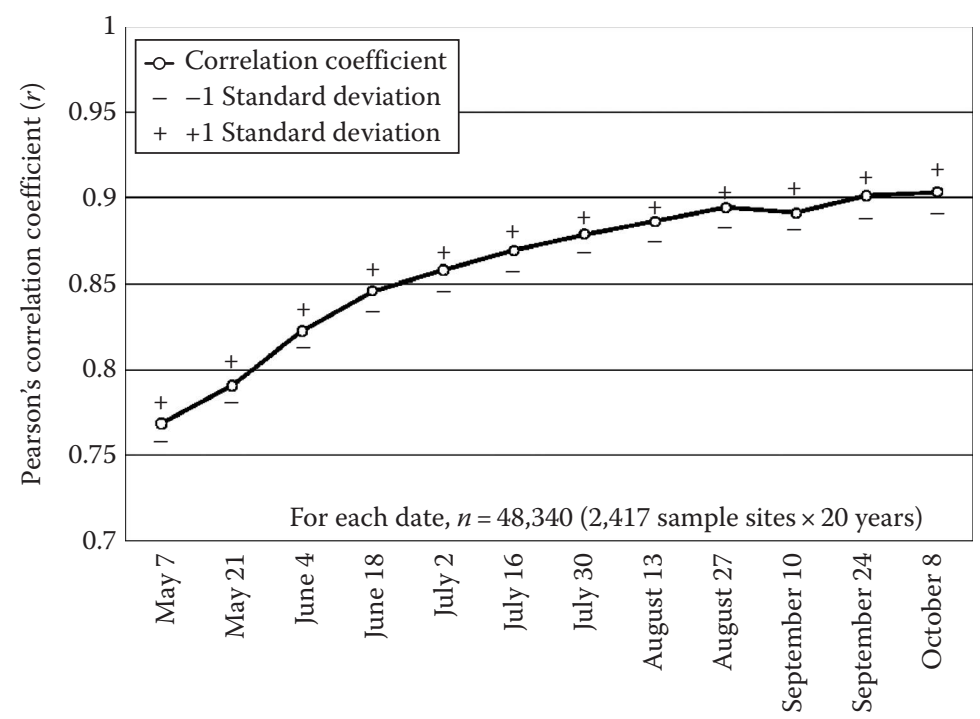

Biweekly periods

FIGURE 3.3 Average Pearson correlation coefficient $(r)$ and variation (standard deviation) between the observed and predicted VegDRI values over a 20 year period (1989-2008) across 2,417 weather station locations of the CONUS for each biweekly period of the growing season. 
biweekly periods. The predictive accuracy gradually increased from May $7(r=0.77)$ to October $8(r=0.90)$. An increase in predictive accuracy early in the growing season might be expected given the inherent interannual variations in the emergence and initial growth rates of vegetation because of varying climatic conditions (e.g., air and soil temperature). Subtle variations in early growing season conditions when the vegetation has relatively low green biomass can result in dramatic changes in PASG values (due to small dynamic range of NDVI values at that time) compared to later in the growing season when the vegetation has much higher biomass and the PASG are less influenced by the same level of variation (due to larger dynamic range of NDVI values). As a result, small changes in vegetation conditions earlier in the year can result in larger PASG changes and thus increased VegDRI error compared to later dates as the growing season progresses when the PASG and resulting VegDRI values are less sensitive to such variations. The period-specific VegDRI models were also found to have a stable predictive accuracy across the 20 year period with relatively low interannual variability among the annual $r$ values for each biweekly period. This is reflected by the small range of the average \pm 1 standard deviation $(\sigma)$ values $(1 \sigma=\sim 0.01)$ that bounded the mean $r$ values for all biweekly periods in Figure 3.3. These results indicate that the performance of VegDRI was reasonably robust over the CONUS across the growing season and relatively uninfluenced by interannual climate variability over two decades.

Because this testing used in situ meteorological observations at each station location to calculate the PDSI validation data sets, these results should be viewed as a "best case" accuracy of VegDRI because calculations in the VegDRI maps for locations between stations are based on spatially interpolated PDSI values (rather than from observed station data). As a result, correlation values in the map lacking in situ observations will likely be lower than those reported here, with the accuracy being highly dependent on the accuracy of the spatial interpolation technique and density of weather station locations in close proximity to that specific location. Further testing is needed to fully assess the overall accuracy of VegDRI for locations lacking in situ-based PDSI data. This could be accomplished by assessing spatially interpolated PDSI grids generated from the station data used in this study or using Parameter-elevation Regressions on Independent Slopes Model (PRISM) or radarbased observed precipitation data from the National Weather Service (NWS) to calculate PDSI values for nonstation locations to compare with the VegDRI results.

\subsubsection{National-LeVel VegDRI: An Example from 2009}

Figure 3.4a and b compares the national VegDRI map for July 13, 2009, with the U.S. Drought Monitor (USDM) map for July 14, 2009, to illustrate the national-level drought patterns and improved spatial resolution of information provided by this index. The USDM (http://drought.unl.edu/dm/monitor.html) represents an appropriate benchmark to compare the performance of VegDRI because it is the current state-of-the-art drought monitoring tool for the United States. The USDM map represents a broad-scale depiction of national agricultural and hydrological drought conditions based on the collective analysis of an array of climate-, hydrologic-, and satellite-based indicators, as well as input from climate and water experts across the 


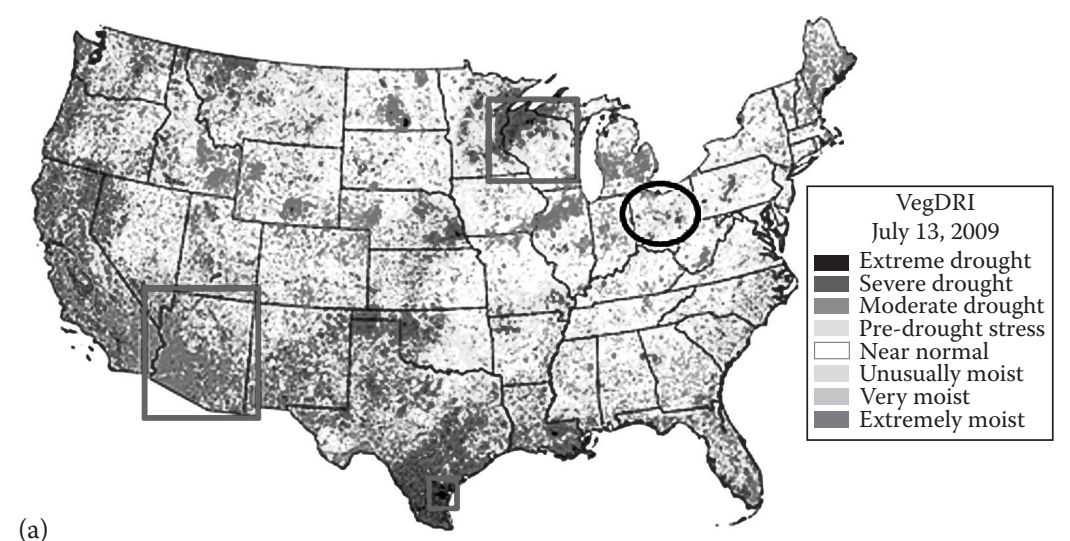

(a)
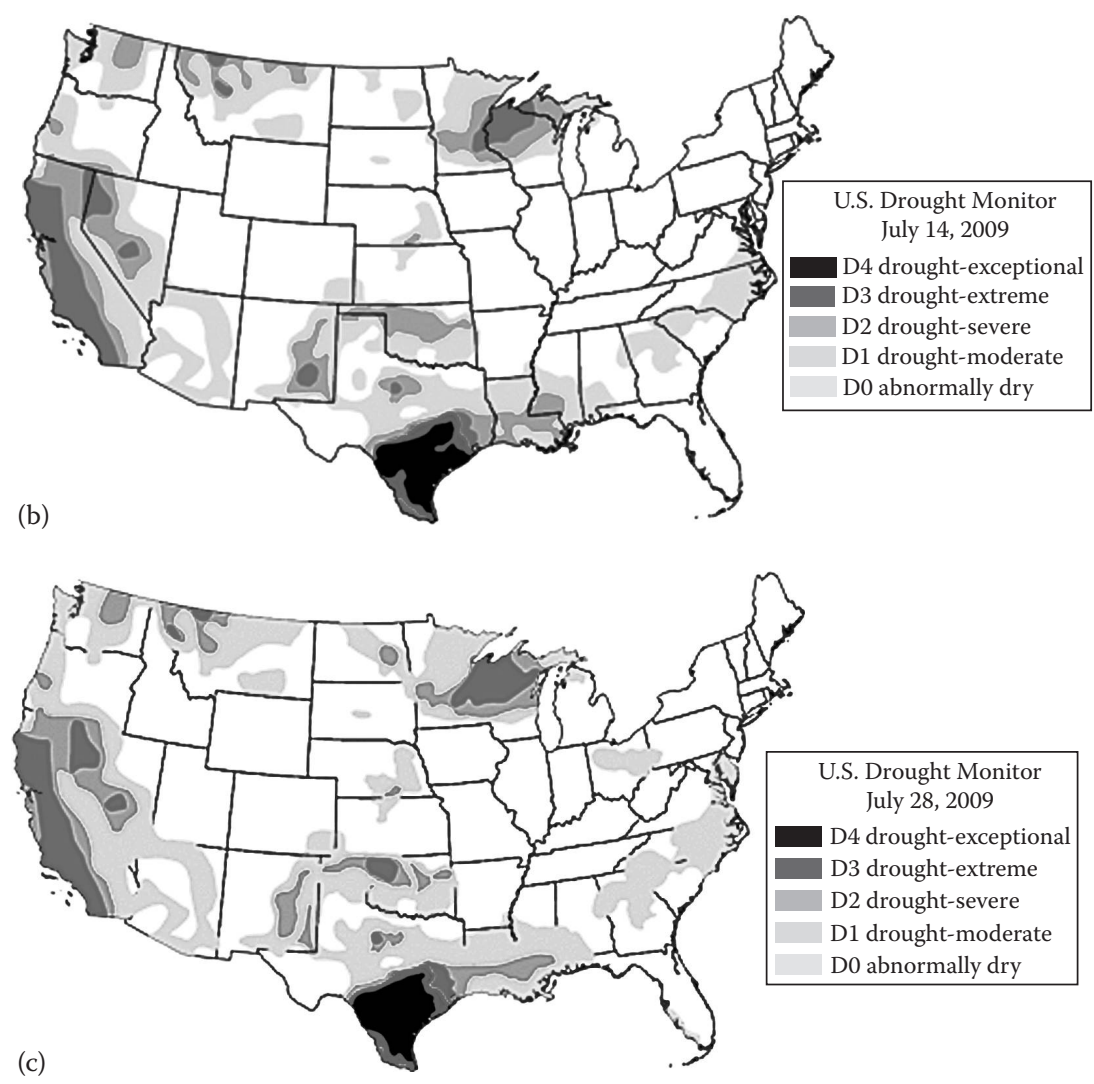

FIGURE 3.4 (See color insert.) VegDRI map (a) for July 13, 2009, and USDM maps for July 14 (b) and July 28 (c), 2009, over the continental United States. The black circle highlights an area of central Ohio that was classified as predrought stress in the VegDRI map but lagged by 2 weeks in the USDM maps, which did not show abnormally dry conditions until late July. The red boxes on the VegDRI map delineate the geographic extent of the local case study areas presented later in Section 3.4. 

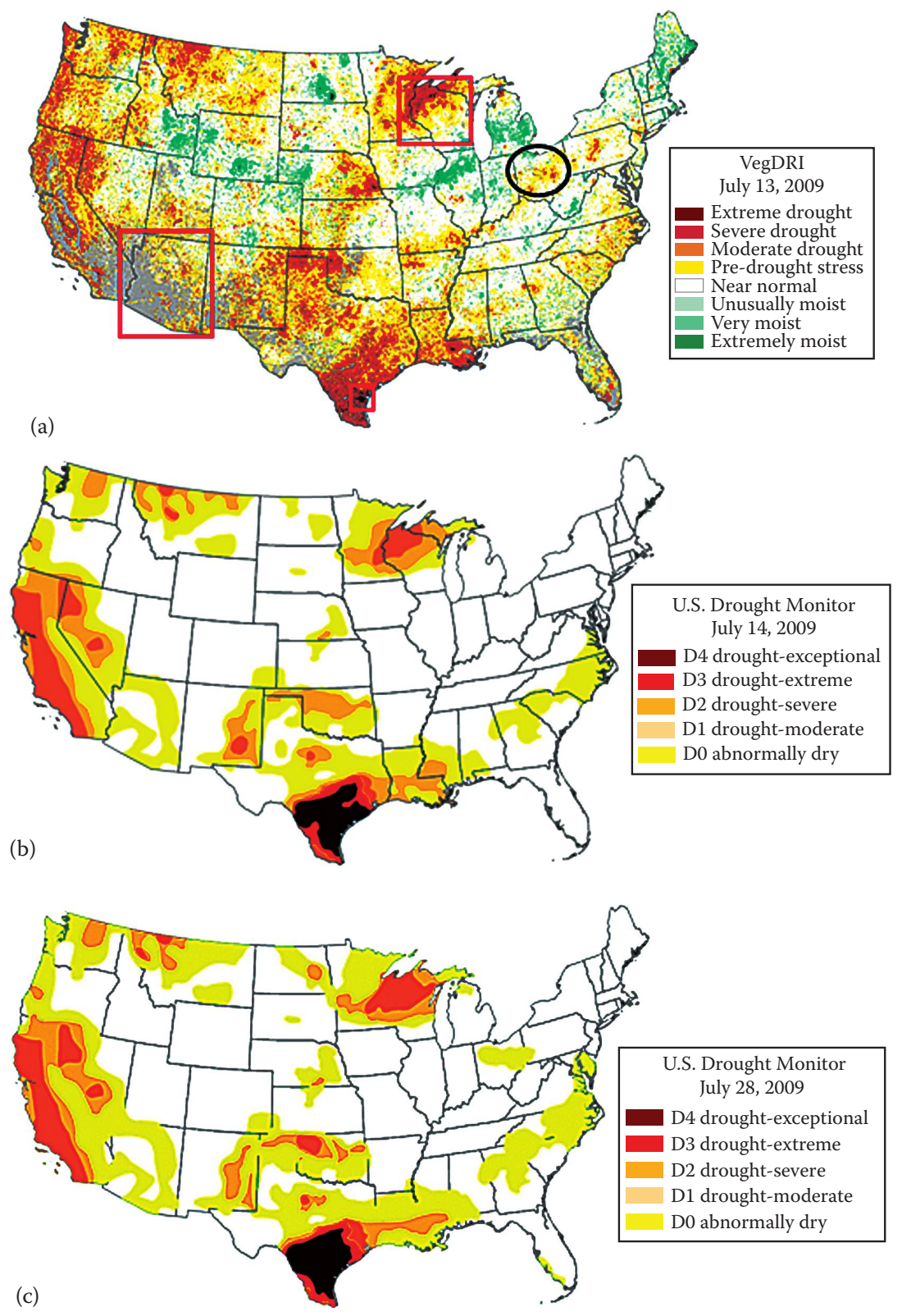

FIGURE 3.4 VegDRI map (a) for July 13, 2009, and USDM maps for July 14 (b) and July 28 (c), 2009, over the continental United States. The black circle highlights an area of central Ohio that was classified as predrought stress in the VegDRI map but lagged by 2 weeks in the USDM maps, which did not show abnormally dry conditions until late July. The red boxes on the VegDRI map delineate the geographic extent of the local case study areas presented later in Section 3.4. 
country (Svoboda et al., 2002). Lower resolution PDSI is one variable commonly used in the construction of the USDM.

VegDRI and the USDM depicted similar drought patterns across the United States for this mid-July 2009 date. Major drought areas such as the severe to extreme conditions in south Texas and moderate to severe conditions in the Oklahoma Panhandle, eastern Minnesota and northern Wisconsin, northwest Montana, and California and western Nevada are seen in both maps. A predrought signal appeared in VegDRI over north Georgia and the Carolinas that was consistent with the abnormally dry areas depicted in the USDM. Small areas of predrought and moderate drought appeared in VegDRI in central Ohio that were absent from the USDM map. However, by late July, similar drought conditions were expressed in the USDM (Figure 3.4c), suggesting that VegDRI may have provided an early indicator of dryness that was not represented in the USDM. Clearly the use of remote sensing information in VegDRI provides higher spatial resolution drought information than that currently conveyed in the USDM. The hope is that indices that incorporate satellite-based observations such as VegDRI will allow the USDM to improve the spatial precision of the drought patterns represented in their maps in the future. The ability of VegDRI to characterize substate to county-level drought patterns over a range of climate regimes and land cover types is further illustrated by the case examples presented in the next section.

\subsubsection{Local-Scale VegDRI Information: Examples from aCross the United States in 2009}

\subsubsection{South Texas}

In 2009, south Texas suffered from severe to extreme drought conditions, with many locations, particularly along the Gulf Coast, experiencing their driest year in the modern climatic data record. Figure 3.5a shows the extreme drought conditions detected by VegDRI over a three-county area centered on Corpus Christi in Nueces County. As the national VegDRI map in Figure 3.4a shows, most of south Texas experienced very severe to extreme drought conditions, but the focal point of the most intense drought signal in VegDRI emerged in the local area of Kleberg, Nueces, and San Patricio counties along the Gulf of Mexico. Precipitation records for several weather stations in these counties (Corpus Christi, Kingsville, Mathis, and Robstown) revealed the magnitude of the 2009 drought, with each station recording its driest year in more than 50 years of precipitation observations. Precipitation deficits were significant, with each station receiving less than $15 \%$ of mean annual rainfall. On average, these humid tropical locations receive more than $54 \mathrm{in}$. of rain annually, but in 2009, they received between 5 and $10 \mathrm{in}$. of precipitation. Agricultural production was devastated with a near-complete failure of two primary crops: cotton and sorghum. For example, USDA (2010a) reported that $29 \%$ of 168,000 planted acres of sorghum were harvested in Nueces County with an average yield of 40 bushels per acre, which ranked as the third lowest production total since 1962. In addition, local media reports collected by the Drought Impact Reporter (http://droughtreporter.unl.edu/) stated that more than $90 \%$ of the cotton and sorghum crops in these counties were destroyed by drought, and the harvestable crop was of poor quality. 


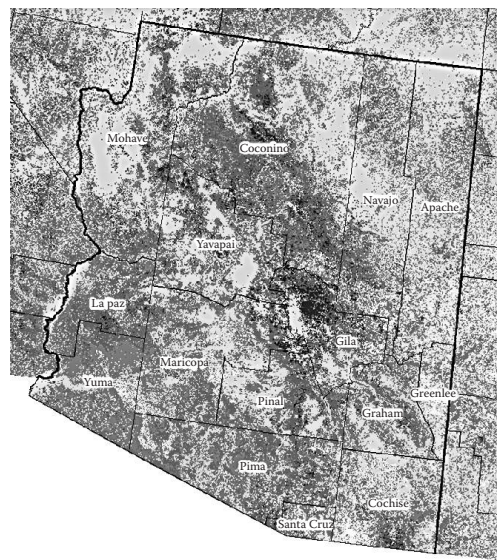

(a)

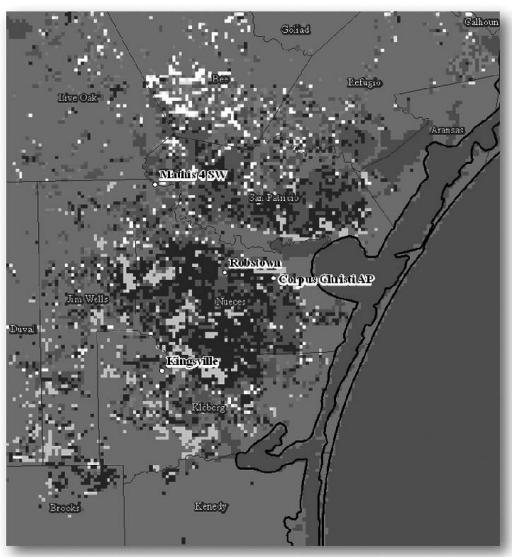

(b)
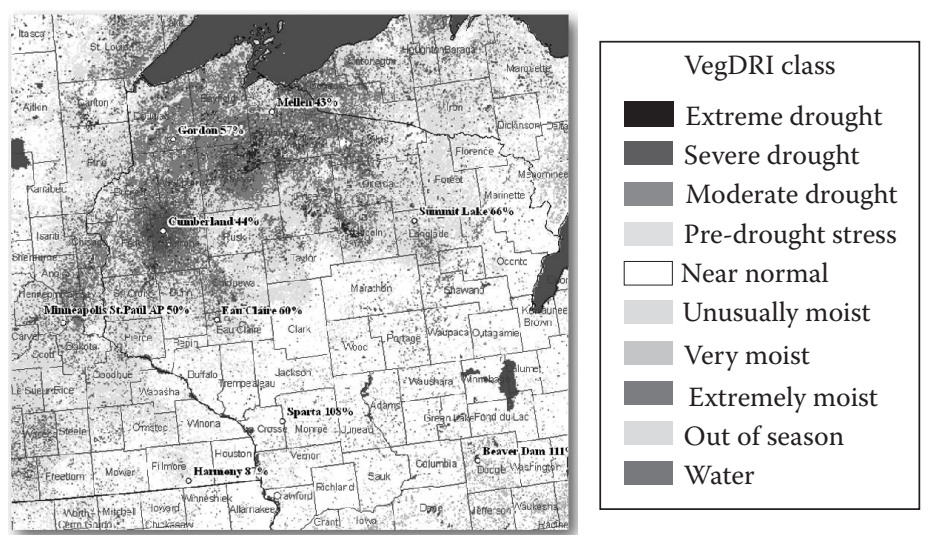

(c)

FIGURE 3.5 (See color insert.) Local-scale VegDRI results on June 29, 2009, over south Texas (a), on November 2, 2009, over the state of Arizona (b), and on August 10, 2009, over eastern Minnesota and northern Wisconsin (percentages for highlighted locations represent the percent of historical average precipitation received at those locations in 2009) (c).

\subsubsection{Arizona}

The severe to extreme drought conditions that were prevalent across Arizona throughout the second half of 2009 are shown in the VegDRI map for November 2 (Figure 3.5b). Drought conditions in Arizona rapidly intensified during the summer and fall because of a lack of rainfall during the monsoon season (July-September), which traditionally accounts for most of the state's annual precipitation in an otherwise arid climate. In 2009, the state of Arizona experienced its third driest June-August period in more than a century (USDA, 2010b). By late October, most of Arizona had received less than $50 \%$ of average precipitation for the year, with the exception of far eastern Arizona, where near-average precipitation was received. VegDRI characterized this rapid progression in drought intensity from predominately near-normal to 


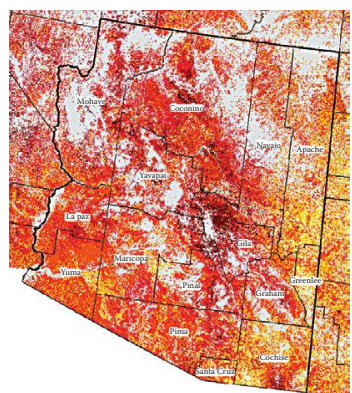

(a)

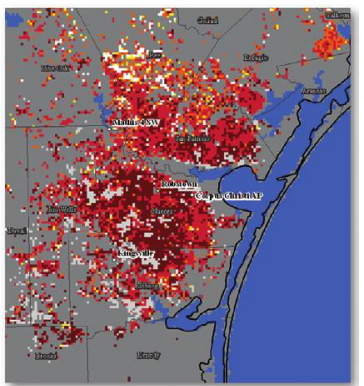

(b)

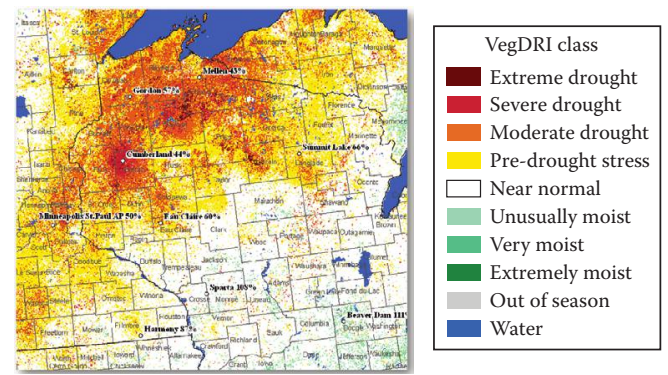

(c)

FIGURE 3.5 Local-scale VegDRI results on June 29, 2009, over south Texas (a), on November 2, 2009, over the state of Arizona (b), and on August 10, 2009, over eastern Minnesota and northern Wisconsin (percentages for highlighted locations represent the percent of historical average precipitation received at those locations in 2009) (c). 
predrought conditions on July 13 (Figure 3.4a) to the severe to extreme drought conditions on November 2 (Figure 3.5b) across most of the state. At the substate level, some of the driest conditions occurred in central Arizona in Coconino, Navajo, and Gila counties, where many locations received $<25 \%$ of average annual precipitation. In Figure $3.5 b$, severe to extreme drought conditions over these counties were reflected in VegDRI. In addition, the more favorable conditions in eastern Arizona in Apache and Greenlee counties are classified in the predrought to moderate drought categories.

The pronounced drought conditions across the state were reflected by the numerous reports of crop losses, degraded rangeland conditions, and negative impacts on forest health. USDA assigned a natural disaster declaration to 13 of 15 counties in Arizona because of substantial agricultural production losses. La Paz and Yuma counties in southwest Arizona were not assigned a disaster declaration because their production losses were not as substantial. The reduced drought severity in this area was depicted by VegDRI in Figure 3.5b, with the majority of Yuma County and much of La Paz County experiencing moderate drought. A time series of VegDRI maps from September through December 2009 (complete VegDRI time series available at http://drought.unl.edu/vegdri/VegDRI_archive.htm) revealed that any severe drought conditions in either county were short lived, and a weaker, moderate drought signal persisted over this period compared to the other western and central counties in Arizona.

\subsubsection{Minnesota and Wisconsin}

A snapshot of the moderate to severe drought conditions that persisted over eastcentral Minnesota and northwest Wisconsin throughout the 2009 growing season is presented in the VegDRI map for August 10 (Figure 3.5c). A band of dry conditions spanning an area from Minneapolis, Minnesota, northeastward to Lake Superior (near Mellen, Wisconsin) began to emerge by early June and continued to intensify to moderate to severe drought conditions by midsummer (mid-July to early August). This example illustrates the local-scale variations in drought patterns depicted by VegDRI, which were consistent with ground observations and impacts reported for this area. The percent average growing season precipitation received by selected weather stations in Figure 3.5c shows that the spatial variations in drought conditions depicted for VegDRI agreed with the rainfall deficit patterns recorded at weather stations across this area. For example, the transition from severe drought conditions in Wisconsin surrounding Cumberland to moderate drought near Eau Claire to near-normal conditions at Sparta classified by VegDRI reflects the localized precipitation gradient recorded during the 2009 growing season between these locations. During the 3 months before August 10, the percent of average precipitation received during that period (typically between 11 and 12 in.) increased along this drought severity gradient from $44 \%$ to $60 \%$ to $108 \%$ for these three locations, respectively. In addition, the core area of moderate to severe drought delineated by VegDRI from Minneapolis to Mellen was consistent with the weather station observations over this area, which typically recorded less than $50 \%$ of average rainfall.

The majority of the drought-stricken area classified as moderate to severe drought in Figure 3.5c is densely forested, and the impact of these dry conditions on vegetation was reflected by an increased number of burn bans and wildfires reported 
in 2009. Foresters in northern Wisconsin reported an increased rate of mortality among several tree species (e.g., oak and maple) primarily attributed to the increased susceptibility of drought-weakened trees to many native insects and pathogens (Schwingle, 2009). Only a small area of extensive cropland between Cumberland, Eau Claire, and Minneapolis was located within the core drought area defined by VegDRI. However, USDA county officials within this area reported dry soil moisture conditions and stressed crops and grasslands by early July that eventually lead to a USDA drought declaration for most counties in east-central Minnesota and northern Wisconsin. Locations classified by VegDRI to have near-normal vegetation conditions south of the core drought area (near stations such as Beaver Dam, Harmony, and Sparta) were not assigned a drought declaration by USDA. This was consistent with USDA National Agricultural Statistics Service (NASS) Crop Progress reports for Wisconsin, which reported adequate rainfall to support agricultural production for this area.

\subsection{ENHANCING VegDRI WITH MODIS SATELLITE DATA}

Work is ongoing to transition the satellite inputs for VegDRI from AVHRR-based NDVI data to a MODIS-based expedited NDVI data stream produced by the USGS eMODIS system (Jenkerson et al., 2010), which has the flexibility to accommodate the production schedule of a specific application (e.g., daily, weekly, or biweekly). The current biweekly AVHRR NDVI composite production schedule is rigid; composites are updated at a 2 week interval on Tuesdays, which restricts the operational production of new VegDRI maps to the middle of the week (i.e., Tuesday or Wednesday) once every 2 weeks. In contrast, the USGS eMODIS system provides a near-real-time, rolling 7 day NDVI composite for the CONUS that allows VegDRI to be updated weekly on Mondays to accommodate the schedule of users such as the USDM authors. In addition, the satellite observations from MODIS used to generate the NDVI data are expected to provide higher-quality information for VegDRI because of improved instrument calibration and higher geolocational accuracy, as well as the rigorous atmospheric and radiometric corrections applied to the spectral data. The eMODIS-based VegDRI will use empirical models incorporating the SOSA and PASG calculated from historical AVHRR NDVI observations that are translated to a "MODIS-like" NDVI time series in order to be consistent with eMODIS NDVI images to which the models are applied for map generation. Development of an AVHRR-to-MODIS NDVI translation algorithm and application within a phenological-based geographic framework (Gu et al., 2010) is nearing completion. eMODIS VegDRI is currently produced at USGS EROS and available via a web map interface (http://vegdri.cr.usgs.gov/viewer/viewer.htm). The transition to operational eMODIS VegDRI production for the CONUS is scheduled for 2011.

\subsection{CONCLUSIONS AND FUTURE WORK}

VegDRI represents a new "hybrid" index for operational vegetation drought monitoring in the United States, incorporating traditional satellite-based VI observations and climate-based drought index data with general biophysical information about the 
environment to produce $1 \mathrm{~km}$ resolution national maps that depict "drought-related" vegetation stress. VegDRI is designed to characterize county to subcounty level drought patterns, which is an appropriate spatial scale to support a wide range of local-scale decision-making activities. Historical testing of the VegDRI models for a 20 year period across the CONUS showed that this index maintained a high predictive accuracy when compared with station-based, self-calibrated PDSI across both the growing season and diverse environmental conditions. Case examples from 2009 over Arizona, south Texas, and northern Minnesota and Wisconsin further illustrated the ability of VegDRI to characterize local-scale variations in drought conditions across a wide range of climatic regimes (i.e., arid to humid) and different land cover types (shrubs, grass, crops, and forest). In addition, model performance was relatively unaffected by interannual climate variations over the two-decade study period. From a national perspective, the major drought patterns classified by VegDRI were consistent with those mapped by the nation's state-of-the-art drought monitoring tool, the USDM, as shown in Figure 3.4a and b. The improved spatial resolution of the $1 \mathrm{~km}$ VegDRI map compared to the USDM map is evident, suggesting that higher resolution inputs such as VegDRI could be used to enhance the spatial precision of the drought patterns depicted in the USDM.

Currently, VegDRI is only operationally produced across the CONUS, but the potential exists to expand this hybrid-based index method to other parts of the world. Satellite-based NDVI observations comparable to those used for VegDRI in the United States are globally available from AVHRR, MERIS, MODIS, and SPOT Vegetation. However, the specific variables used in the biophysical and climate components of VegDRI would be unique for each country or region and depend on the specific data sets that are available. A strength of the VegDRI approach is its flexibility to be customized to the data resources of a given location and its ability to integrate new data inputs as they become available. For example, a temperature component is currently lacking from the VegDRI approach presented in this chapter. However, the potential exists to develop a historical time series of AVHRR thermal observations (or derived ET estimates) that can be integrated into VegDRI to better represent the influence of LST on vegetation conditions. In addition to geographic expansion of VegDRI beyond the United States, the development of a higher spatial resolution VegDRI using MODIS $250 \mathrm{~m}$ NDVI observations is an area of future work to accommodate the needs of local-scale decision makers, who require more detailed landscape-level information that is not contained in the current $1 \mathrm{~km}$ VegDRI products.

Continued validation of VegDRI using multiple information sources (e.g., soil moisture observations, biophysical vegetation measurements, crop/grass production data, and impact reports) is also needed to better characterize index performance over an extended period of time for locations with different environment conditions. Efforts are currently underway to evaluate VegDRI's spatiotemporal performance across the CONUS over two decades (1989-2009) using statistical cross-validation. This work will assess the historical accuracy and variability of VegDRI and investigate the index's performance for major land cover types and different ecological regions of the United States. Comparisons between VegDRI and other drought-related indices and indicators such as the Evaporative Stress Index (ESI) (Anderson et al., 2007, 2010) and the USDM are also being conducted 
to better understand the complementary drought information that VegDRI can provide. Quantitative validation of VegDRI trends with in situ-based biophysical measures of vegetation (e.g., biomass) is also planned, but such long-term data sets are sparse and typically limited to a few long-term ecological reserve sites and research plots maintained by organizations such as USDA's Agricultural Research Service. As a result, VegDRI validation work will utilize a "convergence of evidence" approach that incorporates a range of qualitative and quantitative assessments applied to the broad range of information sources that have been discussed in this chapter to establish the relative strengths and weaknesses of this hybrid drought index.

\section{ACKNOWLEDGMENTS}

Support was provided by the USDA Risk Management Agency (RMA) under USDA partnership 02-IE-0831-0208 with the National Drought Mitigation Center (NDMC), University of Nebraska-Lincoln (UNL), and the U.S. Geological Survey (USGS) (USGS contract 03CRCN0001). The authors thank Deborah Wood of the NDMC for her editorial suggestions.

\section{REFERENCES}

Allen, C.D. and D.D. Breshears. 1998. Drought-induced shift of a forest-woodland ecotone: Rapid landscape response to climate variation. Proceedings of the National Academy of Science 95:14389-14842.

Anderson, M.C., W.P. Kustas, J.M. Norman, C.R. Hain, J.R. Mecikalski, L. Schultz, M.P. Gonzalez-Dugo, C. Cammalleri, G. d'Urso, A. Pimstein, and F. Gao. 2010. Mapping daily evapotranspiration at field to continental scales using geostationary and polar orbiting satellite imagery. Hydrology and Earth System Sciences Discussions, 7:5957-5990.

Anderson, M.C., J.M. Norman, J.R. Mecikalski, J.A. Otkin, and W.P. Kustas. 2007. A climatological study of evapotranspiration and moisture stress across the continental U.S. based on thermal remote sensing: 2. Surface moisture climatology. Journal of Geophysical Research 112: D11112, doi: 11110.11029/12006JD007507.

Breshears, D.D., N.S. Cobb, P.M. Rich, K.P. Price, C.D. Allen, R.G. Balice, W.H. Romme, J.H. Kastens, M.L. Floyd, J. Belnap, J.J. Anderson, O.B. Myers, and C.W. Meyer. 2005. Regional vegetation die-off in response to global-change-type drought. Proceedings of the National Academy of Science 102:15144-15148.

Brown, J.F., S. Maxwell, and S. Pervez. 2009. Mapping irrigated lands across the United States using MODIS satellite imagery. In Remote Sensing of Global Croplands for Food Security, eds. P.S. Thenkabail, J.G. Lyon, H. Turral et al., pp. 177-198. Boca Raton, FL: CRC Press.

Brown, J.F., B.D. Wardlow, T. Tadesse, M.J. Hayes, and B.C. Reed. 2008. The Vegetation Drought Response Index (VegDRI): A new integrated approach for monitoring drought stress in vegetation. GIScience and Remote Sensing 45(1):16-46.

Domenikiotis, C., A. Loukas, and N.R. Dalezios. 2003. The use of NOAA/AVHRR satellite data for monitoring and assessment of forest fires and floods. Natural Hazards and Earth System Science 3(1-2):115-128.

Eidenshink, J.C. 2006. A 16-year time series of $1 \mathrm{~km}$ AVHRR satellite data of the conterminous United States and Alaska. Photogrammetric Engineering and Remote Sensing 72:1027-1035. 
Everard, K., E.W. Seabloom, W.S. Harpole, and C. de Mazancourt. 2010. Plant water use affects competition for nitrogen: Why drought favors invasive species in California. The American Naturalist 175(1):85-97.

Fensham, R.J. and J.E. Holman. 1999. Temporal and spatial patterns in drought-related tree dieback in Australian savanna. Journal of Applied Ecology 36:1035-1050.

Franke, J. and G. Menz. 2007. Multi-temporal wheat disease detection by multi-spectral remote sensing. Precision Agriculture 8(3):161-172.

Gao, G. 1996. NDWI-A normalized difference water index for remote sensing of vegetation liquid water from space. Remote Sensing of Environment 58:257-266.

Goetz, S.J., G.J. Fiske, and A.G. Bunn. 2006. Using satellite time-series data sets to analyze fire disturbance and forest recovery across Canada. Remote Sensing of Environment 101:352-365.

Gu, Y., J.F. Brown, T. Muira, W.J.D. van Leewen, and B.C. Reed. 2010. Phenological classification of the United States: A geographic framework for extending multi-sensor timeseries data. Remote Sensing 2(2):526-544.

Gu, Y., J.F. Brown, J.P. Verdin, and B. Wardlow. 2007. A five-year analysis of MODIS NDVI and NDWI for grassland drought assessment over the central Great Plains of the United States. Geophysical Research Letters 34, doi: 10.1029/2006GL029127.

Gu, Y., E. Hunt, B. Wardlow, J.B. Basara, J.F. Brown, and J.P. Verdin. 2008. Evaluation of MODIS NDVI and NDWI for vegetation drought monitoring using Oklahoma Mesonet soil moisture data. Geophysical Research Letters 35, doi: 10.1029/2008GL035772.

Guarin, A. and A.H. Taylor. 2005. Drought triggered tree mortality in mixed conifer forests in Yosemite National Park, California, USA. Forest Ecology and Management 218:229-244.

Guttman, N.B., J.R. Wallis, and J.R.M. Hosking. 1992. Spatial comparability of the Palmer Drought Severity Index. Water Resources Bulletin 28:1111-1119.

Hayes, M.J., M.D. Svoboda, C.L. Knutson, and D.A. Wilhite. 2004. Estimating the economic impact of drought. Proceedings of the 14th Conference on Applied Climatology, Seattle, WA. ams.confex.com/ams/pdfpapers/73004.pdf

Homer, C., C. Huang, L. Yang, B. Wylie, and M. Coan. 2004. Development of a 2001 national land cover database for the United States. Photogrammetric Engineering and Remote Sensing 70:829-840.

Hubbard, K.G., A.T. DeGaetano, and K.D. Robbins. 2004. SERVICES: A modern applied climate information system. Bulletin of the American Meteorological Society 85(6):811-812.

Jakubauskas, M.E., D.L. Peterson, J.H. Kastens, and D.R. Legates. 2002. Time series remote sensing of landscape-vegetation interactions in the Southern Great Plains. Photogrammetric Engineering and Remote Sensing 68:1021-1030.

Jenkerson, C., T. Maiersperger, and G. Schmidt. 2010. eMODIS-A User-Friendly Data Source. U.S. Geological Survey Open-File Report 2010-1055. http://pubs.usgs.gov/ of/2010/1055/ (accessed June 10, 2011).

Ji, L. and A.J. Peters. 2003. Assessing vegetation response to drought in the northern Great Plains using vegetation and drought indices. Remote Sensing of Environment 87:85-98.

Karnieli, A., N. Agam, R.T. Pinker, M. Anderson, M.L. Imhoff, G.G. Gutman, N. Panov, and A. Goldberg. 2010. Use of NDVI and land surface temperature for drought assessment: Merits and limitations. Journal of Climate 23:618-633.

Karnieli, A., M. Bayasgalan, Y. Bayarjargal, N. Agam, S. Khudulmur, and C.J. Tucker. 2006. Comments on the use of the Vegetation Health Index over Mongolia. International Journal of Remote Sensing 27(20):2017-2024.

Karnieli, A. and G. Dall'Olmo. 2003. Remote-sensing monitoring of desertification, phenology, and droughts. Management of Environmental Quality: An International Journal 41(1):22-38. 
Kasischke, E.S. and M.R. Turetsky. 2006. Recent changes in the fire regime across the North American boreal region-Spatial and temporal patterns of burning across Canada and Alaska. Geophysical Research Letters 33:L09070, doi: 10.1029/2006GL0256767.

Keyantash, J. and J.S. Dracup. 2002. The quantification of drought: An evaluation of drought indices. Bulletin of the American Meteorological Society 83:1167-1180.

Kogan, F.N. 1995. Application of vegetation index and brightness temperature for drought detection. Advances in Space Research 11:91-100.

Kogan, F.N. 1997. Global drought watch from space. Bulletin of the American Meteorological Society 78(4):621-636.

Kogan, F.N. 2002. World droughts in the new millennium from AVHRR-based vegetation health indices. EOS, Transactions of the American Geophysical Union 83:557-564.

Kohavi, R. 1995. A study of cross-validation and bootstrap for accuracy estimation and model selection. In Proceedings of the 14th International Joint Conference on Artificial Intelligence, ed. C.S. Mellish, pp. 1137-1143. San Francisco, CA: Morgan Kaufmann Publishers Inc.

Liu, W.T. and F.N. Kogan. 1996. Monitoring regional drought using the Vegetation Condition Index. International Journal of Remote Sensing 17(14):2761-2782.

Los, S.O., C.O. Justice, and C.J. Tucker. 1994. A global 1 by $1 \mathrm{~km}$ NDVI data set for climate studies derived from the GIMMS continental NDVI data. International Journal of Remote Sensing 15(17):3493-3518.

McKee, T.B., N.J. Doesken, and J. Kleist. 1995. Drought monitoring with multiple time scales. In Preprints, 9th Conference on Applied Climatology, Dallas, TX, pp. 233-236. Boston, FL: American Meteorological Society.

McVicar, T.R. and P.B. Bierwirth. 2001. Rapidly assessing the 1997 drought in Papua New Guinea using composite AVHRR imagery. International Journal of Remote Sensing 22:2109-2128.

NCDC (National Climatic Data Center). 2010. Billion dollar U.S. weather disasters. Disasters chart, http://lwf.ncdc.noaa.gov/img/reports/billion/disasters2009.pdf (accessed June 11, 2011).

Omernik, J.M. 1987. Ecoregions of the conterminous United States. Annals of the Association of American Geographers 77(1):118-125.

Palmer, W.C. 1965. Meteorological drought. Research Paper No. 45, U.S. Department of Commerce Weather Bureau, Washington, DC.

Peters, A.J., S.C. Griffin, A. Vina, and L. Ji. 2000. Use of remotely sensed data for assessing crop hail damage. Photogrammetric Engineering and Remote Sensing 66(11):1349-1355.

Peters, A.J., D.C. Rundquist, and D.A. Wilhite. 1991. Satellite detection of the geographic core of the 1988 Nebraska drought. Agricultural and Forest Meteorology 57:35-47.

Quinlan, J.R. 1993. C4.5 Programs for Machine Learning. San Mateo, CA: Morgan Kaufmann Publishers.

Reed, B.C., J.F. Brown, D. VanderZee, T.R. Loveland, J.W. Merchant, and D.O. Ohlen. 1994. Measuring phenological variability from satellite imagery. Journal of Vegetation Science 5:703-714.

Reed, B.C., T.R. Loveland, and L.L. Tieszen. 1996. An approach for using AVHRR data to monitor U.S. Great Plains grasslands. Geocarto International 11(3):13-22.

Rouse, J.W., R.H. Haas, J.A. Schell, and D.W. Deering. 1974. Monitoring vegetation systems in the Great Plains with ERTS. In Third Earth Resources Technology Satellite-1 Symposium Proceedings, NASA SP351, NASA, Greenbelt, MD, pp. 370-371.

Schwingle, B. 2009. Northern Region Forest Insect and Disease Report. Wisconsin Department of Natural Resources, p. 2, http://dnr.wi.gov/forestry/FH/intheNews/2009/ NOR_Dec2009.pdf (accessed August 21, 2010).

Seiler, R.A., F. Kogan, and J. Sullivan. 1998. AVHRR-based vegetation and temperature condition indices for drought detection in Argentina. Advances in Space Research 21(3):481-484. 
Svoboda, M., D. LeComte, M. Hayes, R. Heim, K. Gleason, J. Angel, B. Rippey, R. Tinker, M. Palecki, D. Stooksbury, D. Miskus, and S. Stephens. 2002. The Drought Monitor. Bulletin of the American Meteorological Society 83(8):1181-1190.

Swetnam, T.W. and J.L. Betancourt. 1998. Mesoscale disturbance and ecological response to decadal climatic variability in the American Southwest. Journal of Climate 11:3128-3147.

Swets, D.L., B.C. Reed, J.R. Rowland, and S.E. Marko. 1999. A weighted least-squares approach to temporal smoothing of NDVI. In Proceedings of the 1999 ASPRS Annual Conference, Portland, OR, May 17-21. Bethesda, MD: American Society for Photogrammetry and Remote Sensing.

Townshend, J.R.G., C.O. Justice, and V. Kalb. 1987. Characterization and classification of South American land cover types using satellite data. International Journal of Remote Sensing 8:1189-1207.

Tucker, C.J., J.E. Pinzon, M.E. Brown, D. Slayback, E.W. Pak, R. Mahoney, E. Vermote, and N. El Saleous. 2005. An extended AVHRR 8-km NDVI data set compatible with MODIS and SPOT Vegetation NDVI data. International Journal of Remote Sensing 26(20):4485-4598.

Tucker, C.J., C.L. Vanpraet, M.J. Sharman, and G. Van Ittersum. 1985. Satellite remote sensing of total herbaceous biomass production in the Senegalese Sahel: 1980-1984. Remote Sensing of Environment 17:233-249.

Unganai, L.S. and F.N. Kogan. 1998. Drought monitoring and corn yield estimation in southern Africa from AVHRR data. Remote Sensing of Environment 63(3):219-232.

USDA (United States Department of Agriculture). 1994. State Soil Geographic (STATSGO) Data Base: Data Use Information. USDA Miscellaneous Publication 1492:1-113.

USDA (United State Department of Agriculture). 2010a. USDA National Agricultural Statistics Service (NASS)—Quick Stats, http://www.nass.usda.gov/QuickStats/Create_ County_All.jsp (accessed June 5, 2010).

USDA (United State Department of Agriculture). 2010b. Weekly Weather and Crop Bulletin. NOAA/USDA Joint Agricultural Weather Facility, Washington, DC., http://www.usda. gov/oce/weather/pubs/Weekly/Wwcb/index.htm (accessed June 11, 2011).

Wan, Z., P. Wang, and X. Li. 2004. Using MODIS Land Surface Temperature and Normalized Difference Vegetation Index products for monitoring drought in the southern Great Plains, USA. International Journal of Remote Sensing 25:61-72.

Wang, L., J.J. Qu, and X. Hao. 2007. Forest fire detection using the normalized multiband drought index (NMDI) with satellite measurements. Agricultural and Forest Meteorology 148:1767-1776.

Wang, Q., M. Watanabe, S. Hayashi, and S. Murakami. 2003. Using NOAA AVHRR data to assess flood damage in China. Environmental Monitoring and Assessment 82(2):118-148.

Wells, N., S. Goddard, and M.J. Hayes. 2004. A self-calibrating Palmer Drought Severity Index. Journal of Climate 17(12):2335-2351.

Westerling, A.L., H.G. Hidalgo, D.R. Cayan, and T.W. Swetnam. 2006. Warming and earlier spring increase western U.S. forest wildfire activity. Science 313:940-943.

Wilhite, D.A. 2000. Preparing for drought: A methodology. In Drought: A Global Assessment, ed. D.A. Wilhite, pp. 89-104. London, U.K.: Routledge.

Williamson, G.B., W.F. Laurance, A.A. Oliveira, P. Delamonica, C. Gascon, T.E. Lovejoy, and L. Pohl. 2000. Amazonian tree mortality during the 1997 El Niño drought. Conservation Biology 14:1538-1542.

Yang, L., B. Wylie, L.L. Tieszen, and B.C. Reed. 1998. An analysis of relationships among climatic forcing and time-integrated NDVI of grasslands over the U.S. northern and central Great Plains. Remote Sensing of Environment 65:25-37. 